\title{
Effect of 12-Week Interventions Involving Nordic Walking Exercise and a Modified Diet on the Anthropometric Parameters and Blood Lipid Profiles in Overweight and Obese Ex-Coal Miners
}

\author{
Ewa Sadowska-Krępa ${ }^{a} \quad$ Agnieszka Gdańska ${ }^{a}$ Michał Rozpara ${ }^{a}$ \\ Wanda Pilch ${ }^{b}$ Miroslava Přidalovác Sebastian Bańkowski ${ }^{a}$ \\ anstitute of Sport Sciences, The Jerzy Kukuczka Academy of Physical Education, \\ Katowice, Poland; ${ }^{b}$ Department of Biochemistry and Basic of Cosmetology, University \\ School of Physical Education, Krakow, Poland; ' Department of Natural Sciences in \\ Kinanthropology, Faculty of Physical Culture, Palacký University, Olomouc, Czech Republic
}

\section{Keywords}

Retirement · Obesity · Lipid disorders · Physical activity · Caloric restriction

\begin{abstract}
Background: Overweight and obesity after retirement are likely to be caused by unhealthy eating habits and the energy intake exceeding the energy expenditure. Objectives: This study was designed to assess the effects of two 12-week interventions involving, respectively, either regular physical activity or a modified lower-calorie diet on the anthropometric parameters and blood lipid profiles in overweight and obese retired miners with lipid disorders. Design: The study participants ( $n=30$, aged $58.7 \pm 4.1$ years, body height $174.8 \pm 7.3 \mathrm{~cm}$, body weight $96.6 \pm 13.9 \mathrm{~kg}$ ) were randomly assigned to 2 intervention groups: the Nordic walking group (NW), which exercised with intensity from 60 to $70 \%$ of participants' maximal heart rates for $1 \mathrm{~h} 3$ times a week, and the modified diet group (MD). Modification of the diet consisted of reducing the daily energy intake by $30 \%$, increasing the dietary content of mono- and polyunsaturated fatty acids and dietary fiber, and reducing the proportion of saturated fatty acids. The variables assessed at baseline and after 6 and 12 weeks were: anthropometric parameters (body weight, fat mass content [FM], fat percentage [BF], BMI, waist circumference [WC], hip circumference $[\mathrm{HC}]$, and waist-to-hip ratio $[\mathrm{WHR}]$ ) and blood lipid indicators (total cholesterol [TC], triglycerides [TG], low density lipoprotein cholesterol [LDL-C], and high density lipoprotein cholesterol [HDL-C]). Results: The body weight of the participants in the NW was lower at week 12 by an average of $5 \mathrm{~kg}, \mathrm{BMI}$ by $6 \%$, FB by $19 \%$, FM by $15 \%$, WC by $8 \%, \mathrm{HC}$ by $6 \%$, and WHR by $3 \%$. In the MD, the respective decreases were $8 \mathrm{~kg}$ and $8,25,20,6,2$, and
\end{abstract}


7\%. In the MD, the postintervention concentrations of TC and TG were within the reference range. Conclusion: Both 12-week interventions improved the anthropometric parameters and blood lipid profiles of retired heavy manual workers, with the improvements being more pronounced in the dieting group.

\section{Introduction}

Unhealthy eating and a sedentary lifestyle are widely reported to cause overweight and obesity. Together with tobacco smoking, type 2 diabetes, and arterial hypertension, they are deemed major risk factors for cardiovascular diseases (CVD) [1, 2]. Overweight and obesity are also associated with dyslipidemia symptomized due to elevated serum lipid and lipoprotein levels [3]. Epidemiological studies have indicated that lipid disorders are the most common and least controlled risk factor for CVD [4].

In preventing overweight and obesity, which lead to lipid disorders, a balance between energy intake and expenditure and consumption of a high-quality nutrient-rich dietare important. Healthy eating guidelines recommend reducing the dietary content of saturated fatty acids (animal fats, coconut, and palm oil) and trans fats (used in cakes and pastries) while increasing the intake of mono- and polyunsaturated fatty acids [5]. A reduction of the intake of carbohydrates (especially the simple ones) is also advised, as well as more fiber-rich foods in the diet [6, 7] as soluble fiber fractions are known to lower the low-density lipoprotein cholesterol (LDL-C) concentration and the glycemic index of foods [8-10]. It is also important to ensure that the daily protein intake meets that recommended for healthy adults, i.e. $1 \mathrm{~g} / \mathrm{kg}$ of body weight [5].

The existing evidence indicates that healthy eating habits and physical activity (PA) are a prerequisite for maintaining a normal body weight [11-15]. According to World Health Organization (WHO) guidelines, obese individuals should increase their PA to $\geq 150 \mathrm{~min} /$ week in order to boost their metabolic rate and energy expenditure and achieve a negative energy balance [16].

PA in obesity treatment is mainly based on low-to-moderate intensity exercises that patients can perform for an extended period of time. The suitability of exercises is assessed in terms of whether they can induce alternating contraction and relaxation of major muscle groups $[17,18]$. One type of exercise that is widely recommended for people with obesity is Nordic walking, i.e., brisk walking with 2 poles which unburden the joints and engage the torso muscles. Typical of Nordic walking are long strides, a rhythmic contralateral gait, and a rolling movement of the foot, starting from the heel through to the toes. It is estimated that $1 \mathrm{~h}$ of moderate-intensity Nordic walking can burn up to 400 calories [19-21].

The job of an underground coal miner is classified among moderate or heavy occupations [22]. An average miner expends, during an 8 -h shift, an average of 2,000 kcal [23]. This energy expenditure is substantial and requires a proportionally large calorie intake. The problem that most miners face after retirement, when their PA is much lower, is that they do not change their eating habits, which exposes them to a higher risk of developing overweight, obesity, and dyslipidemia.

Although healthy eating and PA are known to reduce body weight, overweight, and obesity, switching to a healthy lifestyle is a painstaking process that requires strong self-discipline and willpower to be successful. People with obesity are entangled in a vicious circle: as their weight discourages them from exercise, they tend to avoid PA and so they become more obese. It is therefore important for unhealthy habits to be changed step by step because trying to modify them at once can have a demotivating effect and impair the effectiveness and sustainability of the process $[11,14,24-27]$. 
Given the above context, we set out to compare the effects of two 12-week interventions involving, respectively, adoption of a modified lower calorie diet [28] or increased PA ( $\geq 150$ $\mathrm{min} /$ week as recommended by the WHO and the American Association of Clinical Endocrinologists Medical Guidelines for Clinical Practice) $[16,29]$ on the anthropometric parameters and blood lipid profiles of retired miners with overweight and obesity.

\section{Materials and Methods}

\section{Participants}

The initial sample consisted of 39 ex-coal miners who volunteered to participate in this study. All of the participants lived in the same city in Upper Silesia (Poland) and were recruited by a dietician from among the members of a retired miners' club. All of the volunteers were informed about the purpose of this study and gave their written consent to participate in it. None of them met the exclusion criteria which included: use of tobacco products, alcohol consumption, pharmacological treatment, type 2 diabetes, and arterial hypertension. Following recruitment, participants were randomized into a Nordic walking group (NW, $n=$ 20 ) and a modified diet group (MD, $n=19$ ). Both interventions spanned a period of 12 weeks. Nine participants were removed from this study for noncompliance with the prescribed diet $(n=4)$ and for missing 1 Nordic walking session $(n=5)$. The final number of participants who completed this study was 30 (mean \pm SD: age $58.7 \pm 4.1$ years, body height $174.8 \pm 7.3 \mathrm{~cm}$, body weight $96.6 \pm 13.9 \mathrm{~kg}$; the average length of retirement ranged from 7 to 12 years).

The preintervention levels of PA (PAL; equivalent to the number of steps) were assessed in all of the participants by having them wear uniaxial accelerometers (ActiGraph GT1M; Manufacturing Technology Inc., USA) on the right hip for at least $10 \mathrm{~h}$ a day, every second day, over a period of 1 week. Based on the accelerometers' readings, according to which the participants took from 3,000 to 6,000 steps per day, they were recognized as physically inactive persons [30]. Participants' preintervention energy intake was determined from the food diaries, where they recorded the weight of their meals for 7 days after enrolment [31]. The diaries showed that their daily energy intake exceeded the recommended one by $15 \%$ [32]. Based on interviews held with the participants during the intervention period, it was established that the increased weekly volume of PA did not motivate the participants in the NW to change their dietary energy intake and consumption of a lower-calorie diet did not encourage the participants in the MD to exercise.

The study protocol conformed to the ethical guidelines of the World Medical Association Declaration of Helsinki and was approved by the Ethics Committee of the Jerzy Kukuczka Academy of Physical Education in Katowice, Poland.

\section{Nordic Walking Exercise}

Participants in the NW were given 3 instructional preintervention sessions to familiarize them with the pole walking technique. The regular Nordic walking sessions lasted 60 min (a 10-min warm-up, 45 min of walking, and 5 min of relaxation exercises) and were held 3 times a week. They were led by a certified instructor who made sure that the participants adhered to the Nordic walking rules. The same Nordic walking route was used for all of the sessions. The heart rate monitors (Polar RS 400; Finland) ensured that the exercise intensity ranged from 60 to $70 \%$ of the participants' maximal heart rates $\left(\mathrm{HR}_{\max }\right)$, which were calculated individually using the following formula [33]:

$$
\mathrm{HR}_{\max }=210-0.5 \times \text { age (years) }-0.022 \times \text { body mass }(\mathrm{kg})+4 .
$$


Sadowska-Krępa et al.: Effect of Nordic Walking or a Modified Diet on the

Anthropometric Parameters and Blood Lipid Profiles in Overweight and Obese Men

Table 1. Composition of the participants' diet before the intervention and of the modified diet

\begin{tabular}{lcc}
\hline Diet composition & Baseline diet & Modified diet \\
\hline Energy, kcal & $2,924.6(273.4)$ & $2,062.3(280.9)$ \\
Water, g & $1,169.2(519.2)$ & $1,252.3(172.9)$ \\
Protein, g & $109.3(29.9)$ & $99.7(12.9)$ \\
Energy from protein, \% & 14.9 & 19.5 \\
Fat, g & $117.4(21.5)$ & $76.5(8.3)$ \\
Energy from fat, \% & 36.3 & 33.5 \\
Carbohydrates, g & $340.2(134.8)$ & $230.2(36.9)$ \\
Energy from carbohydrates, \% & 46.4 & 45.1 \\
Dietary fiber, g & $26.6(8.6)$ & $32.3(2.7)$ \\
Saturated fatty acids, g & $67.1(18.6)$ & $15.2(2.0)$ \\
Monounsaturated fatty acids, g & $23.7(12.8)$ & $25.1(3.6)$ \\
Polyunsaturated fatty acids, g & $14.1(4.8)$ & $20.2(1.9)$ \\
Essential fatty acids, g & $12.7(8.6)$ & $16.6(1.6)$ \\
Cholesterol, mg & $674.3(105.5)$ & $432.6(51.4)$ \\
\hline
\end{tabular}

The weekly exercise volume was determined for participants based on the global recommendation of the WHO on PA for health for individuals aged 18-64 years, according to which one should do at least 150 min of moderate-intensity aerobic PA during the week [16].

Diet

Based on the diaries and interviews, the dietician created individual dietary plans for the participants in the MD using Perfect Diet software (Poland). The proportions of nutrients were calculated following the revised dietary norms for the population of Poland [34]. Participants were also instructed to have meals regularly (5 times a day), without snacking in between them, and to have the last meal 3-4 $\mathrm{h}$ before going to bed. To ensure that the participants adhered to the dietary regimen, they had to keep daily food intake logs which were inspected by the dietitian during the weekly obligatory visits. The daily dietary energy intake was cut by $30 \%$ compared to the preintervention level. The dietary content of mono- and polyunsaturated fatty acids was increased, as was that of dietary fiber ( $>30 \mathrm{~g} /$ day). The intake of saturated fatty acids was reduced. The details of the modified diet are shown in Table 1.

\section{Anthropometric Measurements}

Excluding body height, which was only measured at baseline, all other anthropometric parameters were assessed at baseline and then at week 6 and week 12 of the intervention. All measurements were taken in the morning after an overnight fast. Participants' body weight (BW), fat mass (FM), fat percentage (BF), and lean body mass (LBM) were calculated with an InBody ${ }^{\circledR} 570$ Multifrequency Bioelectrical Impedance Analyzer (Biospace Co., Ltd., Seoul, Korea). Waist circumference (WC) was measured in the standing position to the nearest 0.5 $\mathrm{cm}$ at the midpoint between the lowest rib and the iliac crest, and hip circumference (HC) was measured around the largest portion of the buttocks.

\section{Biochemical Analysis}

Fasting blood samples were taken at baseline and at weeks 6 and 12, between 8:00 a.m. and 10:00 a.m. Using the specifications of the clinical chemistry analyzer Alinity ci-series System (Abbott Laboratories), the serum levels of total cholesterol (TC), triglycerides (TG), low-density lipoprotein cholesterol (LDL-C), and high-density lipoprotein cholesterol (HDL-C) were determined. The intra- and interassay coefficients of variation (CV) for the assays were 
Sadowska-Krępa et al.: Effect of Nordic Walking or a Modified Diet on the

Anthropometric Parameters and Blood Lipid Profiles in Overweight and Obese Men

$0.9-1.2,0.5-0.9,0.7-1.6$, and $1.2-1.8 \%$, respectively. The risk of the participants developing CVD was assessed by calculating their lipid ratios (TC/HDL-C, LDL-C/HDL-C, and TG/-C) and atherogenic indices of plasma (AIP) (AIP $=\log _{10}[\mathrm{TG} / \mathrm{HDL}-\mathrm{C}]$, where TG and HDL-C are expressed as molar concentrations) [35].

\section{Statistical Analysis}

Data were reported as means \pm SD. The normality of data distribution was assessed using the Shapiro-Wilk test, homogeneity of variance was determined using the Levene test, and sphericity was evaluated using the Mauchly test. Differences between groups were assessed using a two-way mixed-design ANOVA with 1 within-subjects factor (3 measurement time points, i.e., baseline, week 6 , and week 12 ) and 1 between-subjects factor ( 2 intervention groups: Nordic walking and modified diet). A multivariate ANOVA test was used because the assumption of sphericity was violated. The Bonferroni post hoc test was applied as appropriate. The partial $\eta^{2}$, as a measure of the effect size in the two-way mixed-design ANOVA, was calculated using the following formula: $\eta^{2} p=\mathrm{dfh} \times F / \mathrm{dfh} \times F+\mathrm{dfe}$, where $\mathrm{dfh}$ is a hypothesis degrees of freedom, dfe is an error degrees of freedom, and $F$ is a multivariate ANOVA test value. The values of partial $\eta^{2}$ range between 0 and 1 ( 0.01 , small effect; 0.06 , medium effect; and 0.14 , large effect) [36]. The level of significance was set at $\alpha<0.05$. The statistical analysis was carried out by IBM SPSS Statistics 20 (IBM Corporation, Armonk, NY, USA).

\section{Results}

Table 2 shows the values of anthropometric parameters (BW, FM, BF, LBM, BMI, WC, HC, and WHR) for both groups. A two-way mixed-design ANOVA showed a significant intervention effect on HC ( $p=0.001)$ and WHR $(p=0.029)$, a significant time effect on the anthropometric parameters (excluding LBM) $(p<0.001)$, and a significant intervention-time interaction effect on HC $(p=0.041)$ and WHR $(p=0.020)$. In both groups, BW, FM, BF, BMI, WC, and WHR values recorded at weeks 6 and 12 were significantly lower than at baseline. The $\mathrm{HC}$ of the NW significantly declined between baseline and week 12 . In the MD, its baseline and week 6 values were significantly lower compared to those of the NW (Table 2).

Table 3 shows the values of the blood lipid profile (TC, TG, LDL-C, and HDL-C) and the CVD risk markers (TC/HDL-C, LDL-C/HDL-C, TG/HDL-C, and AIP). A two-way mixed-design ANOVA showed a significant intervention effect on HDL-C ( $p=0.018)$, a significant time effect on lipid indicators $(p<0.001)$ and CVD risk markers $(p<0.001)$, and a significant intervention-time interaction effect on TC $(p=0.046)$, TC/HDL-C $(p=0.001)$, and LDL-C/HDL-C $(p=0.004)$.

The values of TC, TG, LDL-C, LDL-C/HDL-C, TG/HDL, and AIP measured at weeks 6 and 12 were significantly lower than at baseline in both groups, but the postintervention HDL-C proved significantly higher. TC and LDL-C/HDL-C in the MD were found to be significantly lower at weeks 6 and 12 compared to baseline. In the NW, significant decreases in blood lipid profiles (TC, TG, and LDL-C) and CVD risk markers were not noted (Table 3).

\section{Discussion}

The main aim of this study was to evaluate the effects of two 12-week interventions involving, respectively, consumption of a modified lower-calorie diet or maintaining an increased level of PA (Nordic walking) on the anthropometric parameters and lipid profiles on overweight $(n=11, \mathrm{BMI} \geq 25)$ and obese $(n=19$, BMI $\geq 30)$ ex-miners who had led a 
Table 2. Participants' anthropometric parameters at baseline, week 6, and week 12

\begin{tabular}{|c|c|c|c|c|c|c|c|c|c|}
\hline \multirow[t]{2}{*}{ Variable } & \multirow[t]{2}{*}{ Time } & \multicolumn{2}{|l|}{ Intervention } & \multirow[t]{2}{*}{ Effect } & \multirow[t]{2}{*}{$F$} & \multirow[t]{2}{*}{ dfh } & \multirow[t]{2}{*}{ dfe } & \multirow[t]{2}{*}{$p$} & \multirow[t]{2}{*}{$\eta_{p}^{2}$} \\
\hline & & NW & MD & & & & & & \\
\hline \multirow[t]{3}{*}{$\mathrm{BW}, \mathrm{kg}$} & baseline & $96.2(9.9)$ & $97.0(17.4)$ & intervention & 0.0 & 1 & 28 & 0.968 & - \\
\hline & week 6 & $93.1(10.3)$ & $92.7(14.1)$ & time & 39.4 & 2 & 27 & $<0.001$ & 0.74 \\
\hline & week 12 & $90.8(10.8)$ & $89.8(14.9)$ & interaction & 0.6 & 2 & 27 & 0.575 & - \\
\hline \multirow[t]{3}{*}{$\mathrm{FM}, \mathrm{kg}$} & baseline & $31.9(6.2)$ & $32.4(7.3)$ & intervention & 0.0 & 1 & 28 & 0.960 & - \\
\hline & week 6 & $29.6(6.4)$ & $30.8(5.4)$ & time & 21.5 & 2 & 27 & $<0.001$ & 0.61 \\
\hline & week 12 & $27.5(6.1)$ & $26.1(5.6)$ & interaction & 2.1 & 2 & 27 & 0.144 & - \\
\hline \multirow[t]{3}{*}{$\mathrm{BF}, \%$} & baseline & $30.6(6.2)$ & $31.1(7.0)$ & intervention & 0.0 & 1 & 28 & 0.970 & - \\
\hline & week 6 & $27.5(6.3)$ & $28.4(5.6)$ & time & 66.1 & 2 & 27 & $<0.001$ & 0.83 \\
\hline & week 12 & 24.7 (4.9) & $23.2(4.9)$ & interaction & 1.9 & 2 & 27 & 0.168 & - \\
\hline \multirow[t]{3}{*}{ LBM, kg } & baseline & $64.3(12.2)$ & $64.6(20.9)$ & intervention & 0.0 & 1 & 28 & 0.958 & - \\
\hline & week 6 & $63.5(12.5)$ & $61.8(16.4)$ & time & 1.9 & 2 & 27 & 0.165 & - \\
\hline & week 12 & $63.3(14.6)$ & $63.8(17.8)$ & interaction & 1.4 & 2 & 27 & 0.270 & - \\
\hline \multirow[t]{3}{*}{ BMI } & baseline & $31.1(3.4)$ & $32.2(5.6)$ & intervention & 0.2 & 1 & 28 & 0.644 & - \\
\hline & week 6 & 30.1 (3.3) & $30.8(4.7)$ & time & 37.9 & 2 & 27 & $<0.001$ & 0.74 \\
\hline & week 12 & $29.3(3.4)$ & $29.8(5.0)$ & interaction & 0.5 & 2 & 27 & 0.611 & - \\
\hline \multirow[t]{3}{*}{$\mathrm{WC}, \mathrm{cm}$} & baseline & $97.5(8.8)$ & $96.4(13.1)$ & intervention & 0.1 & 1 & 28 & 0.823 & - \\
\hline & week 6 & $93.2(6.5)$ & $93.2(11.7)$ & time & 99.1 & 2 & 27 & $<0.001$ & 0.88 \\
\hline & week 12 & $89.5(6.8)$ & $88.1(10.0)$ & interaction & 2.7 & 2 & 27 & 0.086 & - \\
\hline \multirow[t]{3}{*}{$\mathrm{HC}, \mathrm{cm}$} & baseline & $102.8(11.8)$ & $89.8(5.8)^{\mathrm{e}}$ & intervention & 13.6 & 1 & 28 & $<0.001$ & 0.33 \\
\hline & week 6 & $101.2(9.7)$ & $89.8(6.8)^{\mathrm{d}}$ & time & 13.1 & 2 & 27 & $<0.001$ & 0.49 \\
\hline & week 12 & $96.3(8.0)^{\mathrm{a}, \mathrm{c}}$ & $88.2(6.4)$ & interaction & 3.6 & 2 & 27 & 0.041 & 0.21 \\
\hline \multirow[t]{3}{*}{ WHR } & baseline & $0.96(0.11)$ & $1.08(0.16)$ & intervention & 5.3 & 1 & 28 & 0.029 & 0.16 \\
\hline & week 6 & $0.93(0.09)$ & $1.04(0.14)$ & time & 14.5 & 2 & 27 & $<0.001$ & 0.52 \\
\hline & week 12 & $0.93(0.10)$ & $1.00(0.12)^{\mathrm{a}, \mathrm{b}}$ & interaction & 4.6 & 2 & 27 & 0.020 & 0.25 \\
\hline
\end{tabular}

The total number of participants is 30 . Values are presented as means \pm SD. ${ }^{\mathrm{a}} p<0.001$ vs. baseline. ${ }^{\mathrm{b}} p<0.05$ and ${ }^{\mathrm{c}} p<0.001$ vs. values at week $6 .{ }^{\mathrm{d}} p<0.05$ and ${ }^{\mathrm{e}} p<0.01$ vs. the corresponding values in the NW.

sedentary lifestyle since their retirement. As baseline the level of daily PA of all of the participants ranged from 3,208 to 5,892 steps a day, and they were all classified as physically inactive individuals [30]. Since their retirement from their physically demanding work which required a high energy supply, the study participants were unable to align their eating habits with a new lifestyle and to reduce their daily calorie intake. Their diet consisted mainly of meat products, processed foods, cakes or pastries, and sweet juices, with little fruit and vegetables. Most of the participants showed a preference for foods rich in trans fats and animal fats, rarely consuming products containing plant sterols. The main dietary problems in these groups were a high energy intake exceeding their energy expenditure, overeating, irregular meals, a low intake of liquids, and snacking between meals. It can therefore be assumed that the participants' overweight, obesity, and lipid disorders were caused by limited PA and an unhealthy diet (eating too much and moving too little).

Overcoming the wrong dietary habits, deeply rooted in consciousness, requires genuine consent to reduce the dietary intake or to increase PA. Therefore, we have decided to implement only 1 of these 2 interventions (caloric restriction or Nordic walking exercise) in the lifestyle of ex-miners, so that they do not lose their motivation to participate in this too early. 
Table 3. Participants' blood lipid profiles at baseline, week 6, and week 12

\begin{tabular}{|c|c|c|c|c|c|c|c|c|c|}
\hline \multirow[t]{2}{*}{ Variable } & \multirow[t]{2}{*}{ Time } & \multicolumn{2}{|l|}{ Intervention } & \multirow[t]{2}{*}{ Effect } & \multirow[t]{2}{*}{$F$} & \multirow[t]{2}{*}{ dfh } & \multirow[t]{2}{*}{ dfe } & \multirow[t]{2}{*}{$p$} & \multirow[t]{2}{*}{$\eta_{p}^{2}$} \\
\hline & & NW & MD & & & & & & \\
\hline \multirow[t]{3}{*}{$\mathrm{TC}, \mathrm{mg} / \mathrm{dL}$} & baseline & 233.6 (18.8) & $239.0(25.1)$ & intervention & 2.1 & 1 & 28 & 0.156 & - \\
\hline & week 6 & 222.4 (23.9) & $209.9(14.7)^{b}$ & time & 18.0 & 2 & 27 & $<0.001$ & 0.57 \\
\hline & week 12 & $215.8(26.5)$ & $193.2(29.6)^{c}$ & interaction & 3.5 & 2 & 27 & 0.046 & 0.20 \\
\hline \multirow[t]{3}{*}{$\mathrm{TG}, \mathrm{mg} / \mathrm{dL}$} & baseline & $219.2(56.0)$ & $238.6(55.1)$ & intervention & 0.0 & 1 & 28 & 0.965 & - \\
\hline & week 6 & $182.5(69.0)$ & $176.6(40.6)$ & time & 26.7 & 2 & 27 & $<0.001$ & 0.66 \\
\hline & week 12 & $154.5(60.4)$ & $143.2(51.2)$ & interaction & 1.3 & 2 & 27 & 0.294 & - \\
\hline \multirow[t]{3}{*}{ LDL-C, mg/dL } & baseline & $157.0(34.1)$ & $166.0(34.6)$ & intervention & 0.3 & 1 & 28 & 0.581 & - \\
\hline & week 6 & $143.9(36.1)$ & $133.1(23.4)$ & time & 11.0 & 2 & 27 & $<0.001$ & 0.45 \\
\hline & week 12 & $135.6(45.1)$ & $120.6(26.4)$ & interaction & 1.4 & 2 & 27 & 0.269 & - \\
\hline \multirow[t]{3}{*}{ HDL-C, mg/dL } & baseline & $59.8(16.2)$ & $45.7(11.5)$ & intervention & 6.3 & 1 & 28 & 0.018 & 0.18 \\
\hline & week 6 & $61.1(16.9)$ & $48.3(12.2)$ & time & 5.4 & 2 & 27 & 0.010 & 0.29 \\
\hline & week 12 & $62.3(16.8)$ & $60.9(11.2)$ & interaction & 3.1 & 2 & 27 & 0.063 & - \\
\hline \multirow[t]{3}{*}{ TC/HDL-C } & baseline & $4.3(1.7)$ & $5.5(1.2)$ & intervention & 2.2 & 1 & 28 & 0.148 & - \\
\hline & week 6 & $4.0(1.4)$ & $4.6(1.3)$ & time & 22.6 & 2 & 27 & $<0.001$ & 0.63 \\
\hline & week 12 & $3.7(1.1)$ & $3.2(0.6)^{c, d}$ & interaction & 8.4 & 2 & 27 & 0.001 & 0.38 \\
\hline \multirow{3}{*}{ LDL-C/HDL-C } & baseline & $2.8(1.0)$ & $3.9(1.2)$ & intervention & 1.5 & 1 & 28 & 0.236 & - \\
\hline & week 6 & $2.6(1.1)$ & $2.9(1.0)^{\mathrm{a}}$ & time & 16.6 & 2 & 27 & $<0.001$ & 0.55 \\
\hline & week 12 & $2.4(1.1)$ & $2.0(0.6)^{c, d}$ & interaction & 6.7 & 2 & 27 & 0.004 & 0.33 \\
\hline \multirow[t]{3}{*}{ TG/HDL-C } & baseline & $4.4(2.8)$ & $5.6(1.9)$ & intervention & 1.5 & 1 & 28 & 0.230 & - \\
\hline & week 6 & 3.3 (1.7) & $3.9(1.4)$ & time & 18.2 & 2 & 27 & $<0.001$ & 0.57 \\
\hline & week 12 & $2.6(1.1)$ & $2.5(1.0)$ & interaction & 1.5 & 2 & 27 & 0.236 & - \\
\hline \multirow[t]{3}{*}{ AIP } & baseline & $0.52(0.50)$ & $0.82(0.40)$ & intervention & 1.8 & 1 & 28 & 0.194 & - \\
\hline & week 6 & $0.24(0.50)$ & $0.47(0.40)$ & time & 20.2 & 2 & 27 & $<0.001$ & 0.60 \\
\hline & week 12 & $0.04(0.42)$ & $-0.02(0.47)$ & interaction & 1.6 & 2 & 27 & 0.212 & - \\
\hline
\end{tabular}

The total number of participants is 30 . Values are presented as means \pm SD. ${ }^{\mathrm{a}} p<0.05,{ }^{\mathrm{b}} p<0.01$, and ${ }^{\mathrm{c}} p<0.001$ vs. baseline values. ${ }^{\mathrm{d}} p<0.05$ vs. values at week 6 .

Our study showed that caloric restriction proved to be little more effective in reducing the participants' weight than regular PA. By week 12 of the intervention period, participants in the MD had lost an average of $8 \mathrm{~kg}$ of body weight compared to $5 \mathrm{~kg}$ in the NW. In the first 6 weeks, the average weight loss was $0.5-0.6 \mathrm{~kg}$ per week in both groups. In the next 6 weeks, the average weekly weight loss in the MD was still $0.6 \mathrm{~kg}$, but in the NW it dropped to $0.3 \mathrm{~kg}$. Interestingly, a two-way mixed-design ANOVA indicated a large time effect $\left(0.49 \geq \eta^{2} p \leq 0.88\right)$ on the most anthropometric parameters. Despite the improvement of anthropometric parameters, the differences between the baseline and week-12 values of most of the patients showed a more favorable effect in the MD than in the NW (BMI -2.3 vs. -1.8 , BF -7.9 vs. $-5.9 \%$, and FM -6.3 vs. $4.4 \mathrm{~kg}$ ). Lastly, the post intervention assessments showed that 3 participants in the MD were in the normal BMI range (i.e., <25). However, 12 weeks of Nordic walking exercise done at moderate intensity $\left(60-70 \% \mathrm{HR}_{\max }, \geq 150 \mathrm{~min} /\right.$ week) helped to reduce the participants' $\mathrm{HC}$ by $7 \mathrm{~cm}$, while the calorie-reduced diet reduced their $\mathrm{HC}$ only by $2 \mathrm{~cm}$.

A classical solution recommended for obese patients who wish to lose weight is a weightreduction diet containing fewer saturated fats and monosaccharides and more vegetables, fruits, and cereal grains. It is also important that the diet contain appropriate quantities of complete proteins and vitamins, as well as minerals in amounts close to those recommended 
Sadowska-Krępa et al.: Effect of Nordic Walking or a Modified Diet on the

Anthropometric Parameters and Blood Lipid Profiles in Overweight and Obese Men

by the nutritional standards. In order to be effective, a weight-reducing diet must also respect individuals' dietary habits and be easy to prepare and sustainable [5]. In order to achieve a body mass reduction of $0.5-1.0 \mathrm{~kg} /$ week, a daily energy intake reduction of 600-1,000 kcal is required $[5,6,37]$. It is important to remember that, although the reduction of visceral fat offers metabolic benefits, a fast loss of weight should be avoided because of the risk of lean tissue loss, nutritional deficiencies, and a slower resting metabolism [38].

On the other hand, regular aerobic PA is widely reported as effective in maintaining good health and a proper body weight $[39,40]$. Moderate-intensity exercise has a positive effect on aerobic capacity, the activity of mitochondrial enzymes, and insulin sensitivity [39]. Nordic walking exercise is recommended as safe for obese individuals. It has a positive effect on the human body [19-29]. While walking with sticks, more than $90 \%$ of the muscular system, including the arm, shoulder, and chest muscles, are engaged. Nordic walking also increases the mobility of the joints, relieves pain, improves the aerobic capacity, and tones and shapes the body.

It should be stressed that body weight reduction efforts unaccompanied by caloric restriction are more effective if the duration and intensity of exercise exceed the minimum requirements recommended by WHO [11]. Regrettably, for many physically inactive people, exercising for at least 150 min per week is not achievable or and can even be discouraging [24].

Obesity is well known to be associated not only with insulin resistance and hypertension but also with abnormal lipid metabolism that increases fat storage and atherogenesis [1-3]. In turn, a weight loss of $5-10 \%$ has been shown to reduce the risk of heart disease and stroke [41]. Because baseline measurements showed that participants in both study groups had TC, TG, and LDL-C concentrations outside of the reference range (TC $\geq 200 \mathrm{mg} / \mathrm{dL}, \mathrm{TG} \geq 150 \mathrm{mg} /$ $\mathrm{dL}$, and LDL-C $\geq 100 \mathrm{mg} / \mathrm{dL}$; Table 3) [1-3], we decided to analyze both interventions with respect to their effect on lipid disorders. A two-way mixed-design ANOVA confirmed a large time effect on HDL-C $\left(\eta^{2}{ }_{p}=0.18\right)$, lipid indicators $\left(0.29 \geq \eta^{2} \leq 0.66\right)$, and CVD risk markers $\left(0.55 \geq \eta^{2}{ }_{p} \leq 0.63\right)$ and a large intervention-time interaction effect on TC, TC/HDL-C, and LDL-C/HDL-C $\left(0.20 \geq \eta^{2} \leq 0.38\right)$.

The elevated levels of TG are associated with an increase in small dense LDL particles (sdLDL), which is the main risk factor in the development and progression of atherosclerosis and CVD. Circulating sdLDL particles are very susceptible to multiple atherogenic modifications in blood plasma, including desilylation, glycation, and oxidation, that make them even more atherogenic. Modified sdLDL is a major trigger of inflammatory processes that accompany CVD $[42,43]$. Twelve weeks of exercise in the NW reduced the participants' TG levels to the upper limit of normal [35, 43]. The concentrations of TC/HDL-C (>4.0) and TG/ HDL-C (>3.5), elevated at baseline, fell to normal levels by week 6 and kept falling until the end of the intervention.

The AIP, calculated as a ratio of molar concentrations of triglycerides to HDL-C, is commonly used to assess an individual's risk of developing CVD [42-46], e.g., atherosclerosis or ischemic heart disease [45], with the risk increasing with the AIP value. Dobiásová [46] divided AIP values into 3 intervals representing, respectively, a low risk of CVD ( -0.3 to 0.1 ), a moderate risk (0.1-0.24), and a high risk ( $>0.24)$. The baseline AIP in the NW exceeded 0.5, so the risk of its members developing CVD was substantial. As the AIP values were consistently falling over the period of the intervention, at week 6 the risk dropped to moderate and at week 12 it dropped to low. The ability of regular PA to improve the AIP has also been reported by authors of studies with physically active subjects without lipid disorders [47-49].

Greater differences between the baseline and week-12 levels of TC, TG, and LDL-C in the MD than in the NW ( -45.8 vs. $-17.8 \mathrm{mg} / \mathrm{dL},-95.5 \mathrm{vs} .-64.7 \mathrm{mg} / \mathrm{dL}$, and $-45.4 \mathrm{vs} .-21.4 \mathrm{mg} /$ 
$\mathrm{dL}$, respectively) seem to indicate that caloric restriction was more effective in improving the lipid profiles of participants in the MD. It also caused their TC and TG levels to drop below the upper limit of normal.

The reduction of daily energy intake and diet quality (Table 1) improvement in the MD resulted in a substantial 30\% increase in serum HDL-C. A diet containing a large proportion of saturated fats has been reported to be associated with elevated levels of sdLDL [50], which are a better predictor of CVD than total LDL-C [42-46]. However, it is important to note that reducing the consumption of saturated fats is likely to lead to considerably lower levels of LDL-C and sdLDL $[51,52]$. In our study, the dietary intake of saturated fats was reduced in the MD from around $67 \mathrm{~g}$ /day preintervention to $15 \mathrm{~g}$ (i.e., by almost 77\%). The TC, LDL-C, and TG levels noted at week 12 of the intervention were lower than at baseline. Moreover, the levels of TC/HDL-C (by 40\%), LDL-C/HDL-C ( 47\%), TG/HDL-C ( 55\%), and AIP ( 50\%) were considerably lower, too. The MD AIP dropped between baseline and week 12 from $>0.5$ to below zero (-0.02), indicating that the risk of participants developing CVD decreased from high to low.

\section{Strengths and Limitations}

The main strength of our study is that it deals with a rarely reported case of former heavy physical workers who reduced their PA after retirement to lead a sedentary lifestyle without changing their habitual eating habits, which resulted in a substantial increase in their body weight.

The main limitation of the study is the relatively small number of participants and the lack of a group subjected to both interventions at the same time.

\section{Conclusion}

A healthy diet and regular PA are effective in managing overweight and obesity, but implementing both of these measures at once can be difficult. Therefore, in our study, one group of retired heavy manual workers participated in regular Nordic walking sessions and the other group was on a calorie restriction diet. The postintervention assessments at week 12 showed that, although anthropometric parameters and lipid profiles improved in both groups, in the dieting group they were more pronounced. The findings of our study show the need for further research into the combined effect of dietary intervention and moderate PA, such as Nordic walking, and their potential for preventing obesity and lipid disorders in retired heavy manual workers.

\section{Acknowledgments}

The authors thank Dr. Dominika Stygar for a reviewed first draft of the paper.

\section{Statement of Ethics}

The study protocol was approved by the by the Ethics Committee of the Jerzy Kukuczka Academy of Physical Education in Katowice, Poland (decision No. 4/2013). 


\section{Disclosure Statement}

The authors report no conflict of interests.

\section{Funding Sources}

This study was supported by statutory funds of the Jerzy Kukuczka Academy of Physical Education, Katowice, Poland.

\section{Author Contributions}

E.S.-K.: study concept, writing of this paper. A.G. and S.B.: study concept and methodology. M.R., W.P., and M.P.: analysis and interpretation of data. All of the authors performed critical revision of this paper.

\section{References}

1 Nelson RH. Hyperlipidemia as a risk factor for cardiovascular disease. Prim Care. 2013 Mar;40(1):195-211.

2 Zárate A, Manuel-Apolinar L, Saucedo R, Hernández-Valencia M, Basurto L. Hypercholesterolemia As a Risk Factor for Cardiovascular Disease: Current Controversial Therapeutic Management. Arch Med Res. 2016 Oct; 47(7):491-5.

3 Catapano AL, Graham I, De Backer G, Wiklund O, Chapman MJ, Drexel H, et al.; ESC Scientific Document Group. 2016 ESC/EAS Guidelines for the Management of Dyslipidaemias. Eur Heart J. 2016 Oct;37(39):2999-3058.

4 Arsenault BJ, Boekholdt SM, Kastelein JJ. Lipid parameters for measuring risk of cardiovascular disease. Nat Rev Cardiol. 2011 Apr;8(4):197-206.

5 World Health Organization. Diet, nutrition, and the prevention of chronic diseases: report of a WHO-FAO Expert Consultation. Geneva: WHO; 2003.149 p.

6 Swinburn BA, Caterson I, Seidell JC, James WP. Diet, nutrition and the prevention of excess weight gain and obesity. Public Health Nutr. 2004 Feb;7(1A 1a):123-46.

7 de Souza RJ, Mente A, Maroleanu A, Cozma AI, Ha V, Kishibe T, et al. Intake of saturated and trans unsaturated fatty acids and risk of all cause mortality, cardiovascular disease, and type 2 diabetes: systematic review and meta-analysis of observational studies. BMJ. 2015 Aug;351:h3978.

8 Liang J, Zhou Q, Kwame Amakye W, Su Y, Zhang Z. Biomarkers of dairy fat intake and risk of cardiovascular disease: A systematic review and meta analysis of prospective studies. Crit Rev Food Sci Nutr. 2018 May;58(7): 1122-30.

9 Yanai H, Katsuyama H, Hamasaki H, Abe S, Tada N, Sako A. Effects of Carbohydrate and Dietary Fiber Intake, Glycemic Index and Glycemic Load on HDL Metabolism in Asian Populations. J Clin Med Res. 2014 Oct;6(5): 321-6.

10 Talati R, Baker WL, Pabilonia MS, White CM, Coleman CI. The effects of barley-derived soluble fiber on serum lipids. Ann Fam Med. 2009 Mar-Apr;7(2):157-63.

11 Ross R, Dagnone D, Jones PJ, Smith H, Paddags A, Hudson R, et al. Reduction in obesity and related comorbid conditions after diet-induced weight loss or exercise-induced weight loss in men. A randomized, controlled trial. Ann Intern Med. 2000 Jul;133(2):92-103.

12 Nieman DC, Brock DW, Butterworth D, Utter AC, Nieman CC. Reducing diet and/or exercise training decreases the lipid and lipoprotein risk factors of moderately obese women. J Am Coll Nutr. 2002 Aug;21(4):344-50.

13 Redman LM, Heilbronn LK, Martin CK, Alfonso A, Smith SR, Ravussin E; Pennington CALERIE Team. Effect of calorie restriction with or without exercise on body composition and fat distribution. J Clin Endocrinol Metab. 2007 Mar;92(3):865-72.

14 Cox CE. Role of Physical Activity for Weight Loss and Weight Maintenance. Diabetes Spectr. 2017 Aug;30(3): 157-60.

15 Bocalini DS, Lima LS, de Andrade S, Madureira A, Rica RL, Dos Santos RN, et al. Effects of circuit-based exercise programs on the body composition of elderly obese women. Clin Interv Aging. 2012;7:551-6.

16 World Health Organization. Global recommendations on physical activity for health. Geneva: World Health Organization; 2010.

17 Haskell WL, Lee IM, Pate RR, Powell KE, Blair SN, Franklin BA, et al.; American Heart Association. Physical activity and public health: updated recommendation for adults from the American College of Sports Medicine and the American Heart Association. Circulation. 2007 Aug;116(9):1081-93. 
Sadowska-Krępa et al.: Effect of Nordic Walking or a Modified Diet on the

Anthropometric Parameters and Blood Lipid Profiles in Overweight and Obese Men

18 Spees CK, Scott JM, Taylor CA. Differences in amounts and types of physical activity by obesity status in US adults. Am J Health Behav. 2012 Jan;36(1):56-65.

19 Figard-Fabre H, Fabre N, Leonardi A, Schena F. Efficacy of Nordic walking in obesity management. Int J Sports Med. 2011 Jun;32(6):407-14.

20 Tschentscher M, Niederseer D, Niebauer J. Health benefits of Nordic walking: a systematic review. Am J Prev Med. 2013 Jan;44(1):76-84.

21 Kucio C, Narloch D, Kucio E, Kurek J. The application of Nordic walking in the treatment hypertension and obesity. Fam Med Prim Care Rev. 2017;19(2):144-8.

22 Słota K, Słota Z, Kułagowska E. Thermal load at workstations in the underground coal mining: results of research carried out in 6 coal mines. Med Pr. 2016;67(4):477-98.

23 Humphreys PW, Lind AR. The energy expenditure of coalminers at work. Br J Ind Med. 1962 Oct;19(4):26475.

24 Füzéki E, Banzer W. Physical Activity Recommendations for Health and Beyond in Currently Inactive Populations. Int J Environ Res Public Health. 2018 May;15(5):1042.

25 Hill JO, Wyatt HR. Role of physical activity in preventing and treating obesity. J Appl Physiol (1985). 2005 Aug; 99(2):765-70.

26 Okay DM, Jackson PV, Marcinkiewicz M, Papino MN. Exercise and obesity. Prim Care. 2009 Jun;36(2):379-93.

27 Colberg SR, Sigal RJ, Yardley JE, Riddell MC, Dunstan DW, Dempsey PC, et al. Physical Activity/Exercise and Diabetes: A Position Statement of the American Diabetes Association. Diabetes Care. 2016 Nov;39(11):206579.

28 Raynor HA, Champagne CM. Position of the Academy of Nutrition and Dietetics: Interventions for the Treatment of Overweight and Obesity in Adults. J Acad Nutr Diet. 2016 Jan;116(1):129-47.

29 Garvey WT, Mechanick JI, Brett EM, Garber AJ, Hurley DL, Jastreboff AM, et al.; Reviewers of the AACE/ACE Obesity Clinical Practice Guidelines. American association of clinical endocrinologists and american college of endocrinology comprehensive clinical practice guidelines for medical care of patients with obesity. Endocr Pract. 2016 Jul;22 Suppl 3:1-203.

30 Tudor-Locke C, Craig CL, Brown WJ, Clemes SA, De Cocker K, Giles-Corti B, et al. How many steps/day are enough? For adults. Int J Behav Nutr Phys Act. 2011 Jul;8(1):79.

31 Szponar L, Wolnicka K, Rychlik E. Album fotografii produktów i potraw. Warsaw: Instytut Żywności i Żywienia; 2000.

32 McArdle WD, Katch FI, Katch VL. Essentials of exercise physiology. Philadelphia: Lippincott Williams \& Wilkins; 2010

33 Edwards S. High performance training and racing. Heart Rate Monit Book. 1993;349:113-23.

34 Jarosz M, Rychlik E, Stoś K, Wierzejska R, Wojtasik A, Charzewska J, et al. Normy żywienia dla populacji Polski. Warsaw: Instytut Żywności i Żywienia; 2017.

35 Dobiásová M, Frohlich J. The plasma parameter log (TG/HDL-C) as an atherogenic index: correlation with lipoprotein particle size and esterification rate in apoB-lipoprotein-depleted plasma (FER(HDL)). Clin Biochem. 2001 Oct;34(7):583-8.

36 Richardson JT. Eta squared and partial eta squared as measures of effect size in educational research. Educ Res Rev. 2011;6(2):135-47.

37 Sacks FM, Bray GA, Carey VJ, Smith SR, Ryan DH, Anton SD, et al. Comparison of weight-loss diets with different compositions of fat, protein, and carbohydrates. N Engl J Med. 2009 Feb;360(9):859-73.

38 Santarpia L, Contaldo F, Pasanisi F. Body composition changes after weight-loss interventions for overweight and obesity. Clin Nutr. 2013 Apr;32(2):157-61.

39 Swift DL, Johannsen NM, Lavie CJ, Earnest CP, Church TS. The role of exercise and physical activity in weight loss and maintenance. Prog Cardiovasc Dis. 2014 Jan-Feb;56(4):441-7.

40 Fogelholm M, Kukkonen-Harjula K. Does physical activity prevent weight gain-a systematic review. Obes Rev. 2000 0ct;1(2):95-111.

41 Strychar I. Diet in the management of weight loss. CMAJ. 2006 Jan;174(1):56-63.

42 Ivanova EA, Myasoedova VA, Melnichenko AA, Grechko AV, Orekhov AN. Small dense low-density lipoprotein as biomarker for atherosclerotic diseases. Oxid Med Cell Longev. 2017;2017:1273042.

43 Fan J, Liu Y, Yin S, Chen N, Bai X, Ke Q, et al. Small dense LDL cholesterol is associated with metabolic syndrome traits independently of obesity and inflammation. Nutr Metab (Lond). 2019 Jan;16(1):7.

44 Dobiásová M. Atherogenic index of plasma [log(triglycerides/HDL-cholesterol)]: theoretical and practical implications. Clin Chem. 2004 Jul;50(7):1113-5.

45 Dobiásová M, Frohlich J, Sedová M, Cheung MC, Brown BG. Cholesterol esterification and atherogenic index of plasma correlate with lipoprotein size and findings on coronary angiography. J Lipid Res. 2011 Mar;52(3): 566-71.

46 Dobiásová M. AIP: atherogenic index of plasma as a significant predictor of cardiovascular risk - from research to practice. Vnitr Lek. 2006 Jan;52(1):64-71.

47 Waśkiewicz Z, Kłapcińska B, Sadowska-Krępa E, Czuba M, Kempa K, Kimsa E, et al. Acute metabolic responses to a 24-h ultra-marathon race in male amateur runners. Eur J Appl Physiol. 2012 May;112(5):1679-88.

48 Sadowska-Krępa E, Kłapcińska B, Podgórski T, Szade B, Tyl K, Hadzik A. Effects of supplementation with acai (Euterpe oleracea Mart.) berry-based juice blend on the blood antioxidant defence capacity and lipid profile in junior hurdlers. A pilot study. Biol Sport. 2015 Jun;32(2):161-8. 
49 Pilch W, Tota Ł, Sadowska-Krępa E, Piotrowska A, Kępińska M, Pałka T, et al. The effect of a 12-week health training program on selected anthropometric and biochemical variables in middle-aged women. BioMed Res Int. 2017;2017:9569513.

50 Faghihnia N, Mangravite LM, Chiu S, Bergeron N, Krauss RM. Effects of dietary saturated fat on LDL subclasses and apolipoprotein CIII in men. Eur J Clin Nutr. 2012 Nov;66(11):1229-33.

51 Siri-Tarino PW, Sun Q, Hu FB, Krauss RM. Saturated fatty acids and risk of coronary heart disease: modulation by replacement nutrients. Curr Atheroscler Rep. 2010 Nov;12(6):384-90.

52 Briggs MA, Petersen KS, Kris-Etherton PM. Saturated fatty acids and cardiovascular disease: replacements for saturated fat to reduce cardiovascular risk. Healthcare (Basel). 2017 Jun;5(2):E29. 